\title{
LA INCORPORACIÓN DE LAS ESCRITORAS AL CURRÍCULO LITERARIO EN LA EDUCACIÓN SECUNDARIA: UNA TAREA PENDIENTE ${ }^{1}$
}

\author{
Begoña Lasa Álvarez \\ b.lasa@udc.es \\ Universidade da Coruña- España
}

Recibido: 06-02-2016

Aceptado: 10-05-2016

\section{Resumen}

Tras observar la ausencia casi total de escritoras en los contenidos sobre literatura en la Educación Secundaria, y en particular en la asignatura de Literatura Universal de Bachillerato, en este trabajo se propone su necesaria incorporación. Para ello se ofrecen una serie de claves, pues no se trata de una mera sustitución o adición, sino que la incorporación de diversas voces femeninas debe complementarse promoviendo el interés de su estudio, así como con una reflexión crítica sobre los motivos que han provocado su ausencia de la tradición literaria. Mediante dos escritoras inglesas, Aphra Behn y Charlotte Lennox, cuya transcendencia como novelistas es equiparable a la de sus coetáneos masculinos del siglo XVIII, se ejemplifica esta incorporación.

Palabras Clave: Universal Literature, Baccalaureate, curriculum, canon, women writers, Aphra Behn, Charlotte Lennox.

\begin{abstract}
After observing the almost total absence of women writers in contents about literature in the Secondary Education, and particularly in the subject of Universal Literature in Spanish Baccalaureate, this study proposes their necessary incorporation. Consequently, several key ideas are offered, since a mere substitution or addition are not enough and the incorporation of a number of women's voices needs to be complemented by an interest in their study, along with a critical thought on the motives which have provoked their absence of the literary tradition. Two English writers, Aphra Behn and Charlotte Lennox, whose importance as novelists is comparable to their eighteenth-century male counterparts, are the examples employed.
\end{abstract}

Keywords: Universal Literature, Baccalaureate, curriculum, canon, women writers, Aphra Behn, Charlotte Lennox.

\footnotetext{
${ }^{1}$ Este trabajo ha sido posible gracias al apoyo del Grupo de Investigación CLIN (Literatura y Cultura inglesa moderna y contemporánea, G000274) de la Universidade da Coruña.
} 


\section{Introducción}

Ya en el siglo XXI y a pesar de todos los logros conseguidos, no puede hablarse todavía de una participación igualitaria de mujeres y hombres en todos los ámbitos, especialmente en puestos de liderazgo y de toma de decisiones. Si tenemos en cuenta que la situación de desequilibrio también afecta a los y las profesionales que se encargan de la producción y gestión de los conocimientos vinculados a su elevado cargo de poder, como universidades y medios de comunicación, los hombres igualmente dominan en el oficio de escribir ${ }^{2}$. Sin embargo ¿qué ocurre con la producción literaria, y en especial, con la ficción? Laura Freixas ofrecía algunas respuestas en un artículo que publicaba en el periódico El País con el significativo título de "Qué fue de las escritoras" (Freixas, 2013).

En el resume varios de los pensamientos y opiniones que desarrolló con más detalle en el libro La novela femenil y sus lectrices. La desvalorización de las mujeres y lo femenino en la crítica literaria actual (2009). Señala esta autora que a pesar de que se ha comenzado a hablar de una feminización de la ficción, con destacados titulares que ella cita, en los que se hace referencia a las grandes ventas, al éxito o al "boom" de las escritoras, se trata habitualmente de datos ofrecidos sin rigor alguno (Freixas 2009: 15, 18). Además de que este ensalzamiento del rol de la mujer en la literatura -ya como lectora, ya como escritora- se presenta subrepticiamente como algo negativo, pues aún se considera el éxito de ventas como contrario a la calidad, y por tanto resulta un peligro para la buena literatura (Freixas, 2009: 27).

Por otra parte, en un estudio reciente sobre la presencia, o mejor dicho, la ausencia de mujeres en libros de texto de Educación Secundaria, su autora justifica la utilización de este término, ausencia, a la vista de los resultados de su análisis, pues la proporción de las apariciones de mujeres en el total de manuales analizado, que abarca toda la Educación Secundaria Obligatoria y todas las asignaturas, es ciertamente baja: un $12,8 \%$ de apariciones como personajes, y un 7,5\% como apariciones recurrentes (López Navajas, 2014: n.p.). Pasando a analizar los datos con respecto a la asignatura de Lengua y Literatura Castellana, el porcentaje que arroja este estudio resulta incluso menos alentador, puesto que las apariciones de mujeres como personajes se reducen y pasan a ser de un 11,9\%, y lo mismo ocurre con sus recurrencias, que bajan a un 6,8\% del total (López Navajas, 2004: n.p.).

Para completar estos datos, se va a utilizar un estudio más antiguo realizado por el Instituto de la Mujer en el año 2000 que señalaba en la sección dedicada a mujeres y literatura que solamente el $8 \%$ del total de escritores mencionados en los libros de texto eran mujeres; un

\footnotetext{
${ }^{2}$ Véase, por ejemplo, para la asimetría de género en las universidades: Alonso Sánchez (2002) y Hernández Martín, García-Valcarce Muñoz-Repiso y Sánchez Gómez (2004), y para el caso del periodismo, Rivero Santamaría (2014).
} 
porcentaje que se reduce más si cabe cuando se trata de aquellos autores y autoras que se analizan con mayor detalle, pues es tan sólo del 5\%, y las escritoras mencionadas pertenecen básicamente a dos periodos, al siglo XIX y a la segunda mitad del siglo XX (Instituto de la Mujer, 2000: 160). Estos datos resultan altamente significativos, si tenemos en cuenta que tradicionalmente se ha asumido que la mujer mantiene un vínculo más estrecho con el ámbito de la literatura que con otras disciplinas, fundamentalmente las científicas.

Para intentar paliar esta situación el objetivo de este trabajo es plantear una revisión del currículo literario y proponer la incorporación de escritoras al mismo en la Educación Secundaria, hasta conseguir que progresivamente esté presente el otro $50 \%$ de la población (Rodríguez, 2006: 14).

Ya se han realizado y publicado algunos trabajos, como los de $\mathrm{M}^{\mathrm{a}}$ Victoria Reyzábal (2012) y Carmen Heredero de Pedro (2013), en los que se ofrecen estudios sobre numerosas escritoras que habitualmente no aparecen entre los contenidos de la literatura española. Sin embargo, la materia de Literatura Universal no ha sido examinada desde este punto de vista y se ha descubierto una descompensación similar o incluso más grave, como veremos en el apartado tres de este trabajo. Esta materia se imparte en el primer curso de Bachillerato, una etapa de la Educación Secundaria, que según los objetivos establecidos por la legislación vigente en España (Real Decreto 1105/2014), busca fomentar la igualdad de derechos y oportunidades entre hombres y mujeres, así como que se analicen y valoren críticamente las desigualdades y discriminaciones.

A modo de ejemplo se ha tomado un periodo de entre los que cubre esta materia. Se trata del siglo XVIII o Siglo de las Luces, y dentro de este periodo varios de los contenidos se refieren a la novela inglesa del siglo XVIII, de la que los y las estudiantes se deben ocupar al analizar cuestiones como los orígenes de la novela moderna o los herederos del Quijote en la novela inglesa.

Así pues, tomando como punto de partida estos contenidos en particular, proponemos dar visibilidad a una serie de mujeres que han sido protagonistas y que han aportado reseñables contribuciones a la historia de la literatura, pero que han pasado con frecuencia desapercibidas. Ofrecemos los ejemplos de Aphra Behn (1640-1689) y Charlotte Lennox (1730-1804), con sus obras más representativas: Oroonoko, or the Royal Slave. A True History, que vio la luz en 1688, y The Female Quixote, or The Adventures of Arabella, de evidentes resonancias cervantinas y que se publicó en 1752 , respectivamente ${ }^{3}$.

\footnotetext{
${ }^{3}$ Para su estudio se utilizarán traducciones de los dos textos al castellano.
} 


\section{La asignatura de Literatura Universal en Bachillerato}

En primer lugar y debido a la continua expansión de la agenda de la globalización, que ha afectado de forma singular a los estudios culturales, y en especial a los literarios, se ha observado un reciente resurgimiento del concepto de literatura universal o mundial (D'haen, Domínguez, Rosendahl Thomsen, 2013: x). Un enfoque que ha influido también en los currículos literarios y en los programas educativos, con la inclusión de asignaturas como la que nos ocupa en este trabajo, que lleva esta misma denominación. Sin embargo, la literatura universal no puede dar cabida a todas las obras escritas en todos los tiempos y por todos los pueblos por razones obvias de índole práctico; consiguientemente, el corpus se ha solido reducir tácitamente a los "grandes libros", a las bellas letras de Europa y Norteamérica (Pizer, 2006: 3). Una orientación eurocéntrica, que junto al sexismo ya señalado, se puede apreciar también en los contenidos de la asignatura analizada.

En el currículo para la Educación Secundaria la Literatura Universal es una asignatura troncal opcional de Primer Curso de Bachillerato. De las tres modalidades ofertadas en este nivel educativo, Ciencias, Humanidades y Ciencias Sociales y Artes, la Literatura Universal es una asignatura troncal de opción en las dos últimas. En este documento legal se pone de relieve el papel crucial de esta asignatura para los conocimientos del alumnado sobre el patrimonio cultural del mundo, así como para la valoración crítica de la realidad global contemporánea. Tras una primera parte en la que se abordan contenidos generales, como géneros, formas o temas, que han modelado la historia de la literatura, esta asignatura incluye una segunda parte que analiza los grandes periodos y movimientos de la historia de la literatura universal. Resulta especialmente reseñable que estos dos apartados coinciden en gran medida con las dos dimensiones que Claudio Guillén distinguió en la literatura mundial o Weltliteratur -el término acuñado por Goethe en 1827-: la internacional y la supranacional (2013: 146).

No podemos dejar de mencionar, entre las muchas críticas que ha recibido este nuevo currículo, derivado de la también nueva ley sobre educación, la Ley Orgánica para la Mejora de la Calidad Educativa (LOMCE), un par de ellas que afectan directamente a la asignatura que se analiza. La primera se refiere a la situación de la Literatura Universal, pues esta asignatura con la ley anterior se impartía en $2^{\circ}$ de Bachillerato y con la LOMCE en $1^{\circ}$. En el blog "Me sé cosicas" se considera este cambio totalmente desacertado puesto que el alumnado llega al Bachillerato con un bagaje muy general y escaso de conocimientos sobre literatura y es precisamente en esta etapa cuando se aborda su estudio más a fondo. Con la ley anterior, el alumnado ya en $2^{\circ}$ de Bachillerato se encontraba mejor preparado para enfrentarse a una asignatura de esta naturaleza, pues era en $1^{\circ}$ de Bachillerato cuando se potenciaba el conocimiento literario necesario para ello. La segunda crítica se centra en aspectos más generales de esta nueva ley, como son los currículos sobrecargados, pero que afectan 
directamente también a las asignaturas de literatura. En este caso, en el blog "Eduideas" se incide en la amplitud de los temarios de esta área, que hace imposible que se impartan los contenidos con cierta profundidad, un hecho que evidencia claramente la asignatura de Literatura Universal, pues abarca un período de tiempo amplísimo, básicamente desde la Edad Media hasta la actualidad.

\section{Las escritoras en la asignatura de Literatura Universal: currículo, libros de texto y manuales}

Una vez señalados estos aspectos, lo que se pretende con este estudio es, como ya se ha indicado, la incorporación de escritoras en el currículo literario, con el fin de que el estudiantado sea consciente de lo esenciales que han sido las voces de las mujeres en la experiencia humana en general, pero especialmente en la literatura. También es necesario mostrarles que hay escritores, hombres y mujeres, que han logrado llegar hasta nuestros días gracias a sus creaciones, pues tratan temas, inquietudes $\mathrm{u}$ otras cuestiones que resultan interesantes en la actualidad, e incluso fascinantes por su modernidad. La materia de Literatura Universal que se imparte en Bachillerato brinda al profesorado la posibilidad de ampliar las nociones de los y las estudiantes sobre qué autores y autoras deberían incluirse en la tradición literaria. Este propósito resulta especialmente apropiado para esta asignatura, pues tanto en el currículo del gobierno estatal como en los autonómicos no se especifican los nombres de autores o autoras en los diferentes contenidos que se proponen, exceptuando a Petrarca y Boccaccio en el Renacimiento. Si bien se habla siempre de autores de forma genérica, sin mencionar nunca a posibles autoras.

Vemos pues que el currículo señala unas épocas y movimientos generales, pero sin especificar nombres de escritores o escritoras, con lo que proporciona libertad en este sentido a la hora de llevar a cabo la concreción en las programaciones. Pero obviamente el profesorado tiende a seguir una guía ya establecida, la que ofrecen los libros de texto de dicha materia existentes en el mercado o los manuales, que en un lugar intermedio entre la divulgación y el rigor académico, tratan sobre la literatura universal. Si el currículo ofrece una cierta libertad en cuanto a la selección de los autores y autoras, así como de las obras que se pueden tratar en cada época, los libros de textos vienen a ser los encargados de mantener la uniformidad, proporcionando una tradición selectiva, de tal manera que se enfatizan ciertas áreas o conocimientos, mientras que se olvidan o excluyen otros (Torres Santomé, 2003: 99). Por lo que se refiere a la presencia de escritoras, en los libros de texto de la asignatura de Literatura Universal consultados y examinados - Editorial Xerais (Abilleira Sanmartín y Gestido de la Torre, 2009), Editorial Anaya (Gutiérrez Ordóñez, Serrano Serrano y Hernández García, 2015) y Editorial Casals (Arévalo Martín et al., 2015)-, aunque sea en diferente proporción, resulta 
evidente la gran diferencia existente entre el número de autores y autoras presentes en los mismos.

El libro de texto de Anaya es en el que el número de mujeres es inferior, aunque cabe resaltar que también es el menos denso, los temas no son muy extensos y hay un menor número de escritores/as y obras en general. De épocas anteriores al siglo XX, únicamente se menciona a la poeta griega Safo y a la novelista inglesa Jane Austen en el Romanticismo. Ya en el siglo XX se dedica cierto espacio a Virginia Woolf, Marguerite Yourcenar y Doris Lessing, y sólo se menciona a Natalie Sarraute y Marguerite Duras, así como a Gertrude Stein. En el último tema del libro curiosamente se incluye una sección sobre "Narrativa escrita por mujeres", en la que se indican una serie de características específicas de la misma, pues "aporta nuevos puntos de vista, nuevos problemas y nuevos temas a la literatura" (Gutiérrez Ordóñez, Serrano Serrano y Hernández García, 2015: 241). Se estudian brevemente tres autoras: Flannery O’Connor, Toni Morrison y Alice Walker. Este apartado especial dedicado a las escritoras es precisamente el último del último tema del libro, apreciándose claramente que es una especie de añadido o apéndice que se conjuga de manera más o menos armoniosa con el resto y que por su situación complementaria puede considerarse un contenido prescindible y que posiblemente no llegue a impartirse (Espigado Tocino, 2004: 140-141), dado el volumen de temas que, como ya se ha señalado anteriormente, caracteriza a esta materia.

El libro de texto sobre Literatura Universal de la editorial Casals es notablemente más extenso que el anterior, por lo tanto, se aprecia un número más elevado de autores y autoras en general y también de obras mencionadas y textos para lectura y análisis. Así, el número de autoras presentes es mayor y se les dedica algo más de espacio, pero el porcentaje con respecto al número de escritores es similar al del libro anterior. Vuelven a aparecer Safo y Jane Austen, aunque ésta aparece dentro del tema del Siglo de las Luces y no del Romanticismo en este caso, pues al tratarse de una escritora a caballo entre las dos épocas suele producirse esta indeterminación. La escritora Mary Shelley recibe considerable atención, así como su novela, Frankenstein. Así mismo se habla de Mme de Staël, se menciona brevemente a las hermanas Brontë, a Emily Dickinson, Ingeborg Bachmann, Gertrude Stein, también a Sylvia Plath y Anne Sexton. Más adelante, en la narrativa encontramos a Edith Wharton, pero es Virginia Woolf la mujer a quien más espacio se dedica en este tema. Brevemente se menciona también a Marguerite Duras y Natalie Sarraute, a Agatha Christie, Patricia Highsmith, Marguerite Yourcenar, Susan Sontag, Doris Lesing y Nadine Gordimer. Así enumeradas, resulta un número considerable de autoras, pero apenas una insignificancia comparado con el de los hombres.

La editorial Xerais publica libros de texto en lengua gallega para la Comunidad Autónoma de Galicia; así pues, el libro que se ocupa de la materia de Literatura Universal presenta como característica más destacada un propósito palpable por situar a autores y autoras en lengua gallega en relación con las diversas corrientes y movimientos de la literatura universal. También realizan un esfuerzo inclusivo mayor y tratan de referirse no solo al ámbito occidental, sino también a otras culturas y otras lenguas. Su catálogo de escritoras es asimismo más amplio, 
apreciándose un intento de incluir a alguna mujer en todas las épocas. Así, por ejemplo, en el medievo mencionan a María de France, Rosvita de Gandersheim e Hildegarde de Bingen, señalando en el caso de estas dos últimas que se trata de potentes personalidades y obras muy significativas para la historia del discurso femenino, en un contexto tan dominantemente masculino como el medieval (Abilleira Sanmartín y Gestido de la Torre, 2009: 191).

Es en este libro donde se encontrará una mayor reflexión sobre los motivos por los que hay muchos menos productos literarios escritos por mujeres, aunque como vimos anteriormente, se hace en una última sección del penúltimo tema del mismo, con la consecuencia que esto puede tener. El alumnado podrá leer aquí una explicación bastante amplia sobre el porqué del silencio y marginación a los que han sido sometidas las mujeres en la literatura y las circunstancias que han llevado a que no haya sido hasta el siglo XX en que se ha producido un auténtico florecimiento de mujeres como autoras literarias. Explican también la construcción social de las diferencias entre sexo y género, que dan lugar a la relación jerárquica establecida entre hombres y mujeres. Esta desigualdad llevada a la literatura supone que los hombres ocupan el centro, el canon literario, y las mujeres son relegadas a la marginalidad, a capítulos aparte y aislados, que es precisamente la misma injusticia en la que caen los autores, al crear esta sección específica y complementaria para hablar de la literatura escrita por mujeres (Abilleira Sanmartín y Gestido de la Torre, 2009: 394-398).

Resulta significativo, sin embargo, que a pesar del escaso número de escritoras que pueblan estos libros de texto, la mujer sí que esté presente en ellos, pero con un papel totalmente distinto al de creadora, puesto que adquiere gran protagonismo, especialmente en alguno de los periodos literarios, como musa e inspiración de escritores. Tal es el caso de la dama en la poesía cortesana medieval, del tópico de la Donna Angelicata en la poesía italiana del Renacimiento, de las numerosas protagonistas femeninas de la novela decimonónica o de la femme fatale de principios del siglo XX. Destaca en este sentido el texto de Xerais, pues dedica un apartado del tema sobre el Realismo y Naturalismo a los personajes femeninos de las obras más representativas de este periodo (Abilleira Sanmartín y Gestido de la Torre, 2009: 301-304). Efectivamente, algunas de estas heroínas se han convertido en iconos y símbolos, como Jane Eyre, Madame Bovary o Anna Karenina, entre otras, pero por representar ciertos aspectos y temas que se han considerado tradicionalmente asociados al universo femenino, como son el sexo, el amor o la maternidad, y que se definen siempre por su relación con los hombres (Freixas, 2005: n.p.).

Por otra parte, cualquier persona que quiera acercarse al tema de la literatura universal y conocer de una forma condensada y agrupada el vasto legado literario que han dejado los escritores y escritoras a lo largo de la historia puede acceder a estos conocimientos mediante manuales clásicos, como los de De Riquer y Valverde (2010) y Llovet (2012), o menos convencionales, como el trabajo de Posteguillo (2012). Como en los libros de texto, en estos manuales el foco se dirige prácticamente con exclusividad a la literatura occidental, ofreciendo en todo caso algún apartado específico sobre literaturas orientales, por ejemplo. En lo que se 
refiere a la presencia femenina en ellos es también escasa; baste decir a modo de ejemplo que de los 107 textos o lecciones que incluye el voluminoso Lecciones de literatura universal de Llovet únicamente dos están dedicados a escritoras (Jane Austen y Virginia Woolf), 16 son generales sobre géneros y/o periodos literarios y el resto se centran en un escritor. Igualmente, en el de Posteguillo, de los 24 capítulos de que consta el texto, sólo 5 están enteramente dedicados a mujeres (Mary Shelley, Jane Austen, Rosalía de Castro, Anne Perry y J.K. Rowling). Finalmente, en los dos volúmenes de la Historia de la literatura universal de De Riquer y Valverde, la mayoría de las secciones son generales sobre periodos, géneros o países, pero hemos observado que ningún apartado importante está dedicado a alguna escritora, aparecen únicamente en subapartados y en algunos de ellos compartiendo protagonismo. Se trata de María de Francia, la Condesa de Día y Margarita de Navarra en el primer volumen; y de Madame de Staël, Las Brontë y George Eliot, Emily Dickinson, Rosalía de Castro, Gabriela Mistral y Virginia Woolf en el segundo.

\section{Claves para la incorporación de las escritoras al currículo literario}

Carmen Servén, partiendo del hecho que procedemos de una cultura sexista y que por tanto ha creado un canon literario también sexista, señala que al profesorado de literatura le corresponde orientar la experiencia axiológica en que consiste la lectura literaria, reinterpretando y actualizando los mensajes de los textos literarios (Servén Díez, 2008: 10). Por tanto, aparte de dar visibilidad a algunas escritoras, nuestro objetivo será poner de manifiesto que no sólo las destacadas aportaciones de los novelistas fueron decisivas en el desarrollo de la novela, sino también las de las novelistas, aunque no siempre se les haya reconocido este papel, como le ha ocurrido a Aphra Behn. Obviamente, nuestra propuesta no dejará de ocuparse de los grandes nombres de la novela en lengua inglesa del siglo XVIII: Daniel Defoe, Henry Fielding y Samuel Richrdson, conocidos como the fathers of the English novel, además de Jonatham Swift o Lawrence Sterne; pero no debemos olvidar que las obras de escritoras de finales del siglo XVII y principios del XVIII, como la citada Behn, Eliza Haywood o Penelope Aubin, obtuvieron tanto o más éxito de público que los textos de los novelistas canónicos (Warner, 2005: 87), lo que llevó a investigadoras como Jane Spencer (1986), Janet Todd (1989) o Dale Spender (1986) a incorporar también a las escritoras a la historia de la novela inglesa y utilizar la frase mothers of the novel (Spender, 1986).

Lo mismo ocurre cuando se menciona el tema de la influencia del Quijote en la novela inglesa del siglo XVIII, pues siempre se cita a los mismos autores, es decir, Henry Fielding, Laurence Sterne o Tobias Smollett, mientras que se suele olvidar a un importante grupo de escritoras del siglo XVIII, que tomaron como referencia el personaje de Don Quijote para construir sus textos narrativos. 
En este sentido, se podría mencionar el corpus ofrecido por John Skinner, quien en un esfuerzo por tener en cuenta tanto fuentes de la época, como de la actualidad, ha llegado a formular una lista de 50 novelistas dieciochistas, que incluye a 23 mujeres y 27 hombres en activo durante este periodo y con obras reconocidas (2001: 51). Lo que demostraría que existió una igualdad prácticamente total en cuanto a sexos en lo que se refiere al desarrollo de una carrera literaria, siendo incluso alguna de las novelistas más conocida y con más ediciones y ventas que sus coetáneos, como se acaba de indicar.

También resulta significativo que en el siglo XVIII en Gran Bretaña fuese casi un lugar común señalar la masiva entrada de las mujeres en el ámbito de la escritura; aunque en realidad se trataba de verbalizar una especie de amenaza que podía desestabilizar el statu quo masculino, puesto que seguían sin ser aceptadas por su atrevimiento y falta de modestia, o en el mejor de los casos, eran tratadas con condescendencia por la crítica (Lasa Álvarez, 2010: 192). En cualquier caso, parece claro que en esta época en Inglaterra el número de escritoras de novelas es elevado, con lo que resultaría bastante sencillo introducir a alguna de ellas entre los contenidos a tratar. Sin embargo, por incomprensible que parezca, no es así.

John Guillory en su estudio sobre la formación del canon literario ha subrayado el papel fundamental desempeñado por las instituciones educativas en su formación, considerando el canon como una lista imaginaria que se forja mediante los múltiples currículos individuales surgidos dentro de instituciones pedagógicas individuales a lo largo de un periodo de tiempo considerable (1993: 31). Esta definición de canon destaca por su naturaleza fluida y relativa, lo que posibilita que puedan añadirse y eliminarse obras sin alterar la impresión que provoca de totalidad o de homogeneidad cultural (Guillory, 1993: 33). En cualquier caso, de las dos estrategias institucionales mencionada por este autor: la incorporación de obras no canónicas en el currículo o el establecimiento de currículos separados o alternativos (Guillory, 1993: 9), la opción por la que nos decantamos en este estudio es sin duda la primera, al proponer el estudio de los padres de la novela junto a dos de sus madres.

En cuanto al profesorado, se le suele considerar como agente pedagógico que define y controla lo que es válido y relevante en el aula, tanto en cuanto a conocimientos como valores (Coffey y Delamont, 2000: 29). Sin embargo, ¿qué conocimientos y qué valores están transmitiendo los profesores y las profesoras cuando existe un currículo oficial prescrito tanto por el gobierno nacional, como el regional en España? Para Coffey y Delamont este hecho no implica que dicho currículo oficial no se pueda cuestionar desde un punto de vista feminista (2000). En su día a día en el aula el profesorado disfruta de una relativa autonomía en la toma de decisiones, lo que le brinda constantes oportunidades de empoderamiento y en consecuencia, de ensanchar las mentes de los y las estudiantes con nueva información.

En el mismo sentido, Gaby Weiner recalca la posibilidad de una mayor fluidez en la relación entre el gobierno, que propone el currículo, y el profesorado, que es quien lo interpreta, y por tanto, esta interpretación depende de la multiplicidad de subjetividades, y deja siempre un margen de maniobra (1999: 148). Es por esto que propone al profesorado el cuestionamiento de 
las universalidades y certezas predominantes en los currículos y la adopción de una praxis y unos enfoques pedagógicos alternativos basados en el feminismo, para conseguir que el alumnado se acerque de forma crítica a las "verdades académicas" de sus manuales y acoja con interés otros posibles contenidos que se les ofrezca (Weiner, 1999: 149-150).

En cuanto al ámbito literario, $\mathrm{M}^{\mathrm{a}}$ Victoria Reyzabal señala que para visibilizar a tantas mujeres acalladas y marginadas durante siglos, no sólo es necesario el redescubrimiento de muchas voces femeninas, sino también explorar y profundizar en otros aspectos como la idea implícita generalizada a través del canon de que el trabajo literario de las mujeres ha sido inferior o marginal y alertar a las generaciones actuales sobre esta discriminación en la selección de escritores y escritoras; paralelamente, propone animar a las jóvenes a que traten de encontrar cauces de expresión propios y que no se apoyen en los que se les ofrece habitualmente, pues provienen de una selección sesgada (2012: 22). Por otra parte, la didáctica de la literatura resulta un instrumento muy valioso y necesario para la educación en valores al ayudar a conocer la propia cultura y a entender la sociedad en que vivimos (Soldevila, 2006: 21). En el caso de la asignatura de Literatura Universal y en especial por su enfoque comparativo, contribuye a fomentar la tolerancia y una mejor convivencia, al poner a los y las estudiantes en contacto con otras culturas y otras formas de ver la realidad, lo que a su vez favorece el desarrollo de su espíritu crítico (Fuentes Moreno, 2013: 83).

Para llevar a la práctica todo lo anterior se ha utilizado en este trabajo la estrategia en dos pasos de Regina Buccola para su proyecto de implantar nichos para las mujeres en el currículo, pues considera que hay dos aspectos básicos en los que hay que trabajar: en primer lugar, el estudiantado debería llegar a ver a las escritoras como parte integral de la historia de la literatura y no como algo excepcional, y en segundo, deberían valorar la importancia de llevar a cabo estudios sobre sus obras por lo que significan para darles una progresiva visibilidad (2003: 148).

\section{Aphra Behn}

En primer lugar, para realizar la presentación de esta escritora, que les resultará totalmente desconocida a los y las estudiantes, comenzaremos con unas palabras de otra escritora, Virginia Woolf (2008: 49), sobre ella: "Todas las mujeres deberían echar flores sobre la tumba de Aphra Behn, [...] porque fue ella quien conquistó para ellas el derecho a decir lo que les parezca" para que comenten qué es lo que les sugieren. Posteriormente, serán ellos y ellas quienes descubran a Behn, pues de esta manera la lectura posterior será aprovechada y sobre todo disfrutada con mayor intensidad y profundidad (Diard y Bordons, 2005: 69-70). Utilizaremos las enormes posibilidades que nos ofrece la red y buscarán páginas web sobre la biografía de Behn y su contexto, como Wikipedia, Lecturalia o BBC. Para completar esta información recurriremos a 
diversos textos o fragmentos procedentes de biografías sobre Behn que se publicaron en colecciones de vidas de mujeres ilustres ya en los siglos XVIII y XIX. Metodológicamente, este estudio resulta doblemente fructífero, puesto que, además de conocer la vida de la escritora, los alumnos y alumnas podrán observar un aspecto de las biografías sobre mujeres que lamentaba Mary Hays, una de las compiladoras de biografías que utilizaremos. Señaló acertadamente que en estos textos se puede apreciar el doble rasero con el que las escritoras eran consideradas, pues la vida de éstas se sometía a un escrutinio mucho más severo que la de los hombres, y además, pasaba a formar parte de la opinión pública tanto o más que sus obras, leyéndose estas últimas, por tanto, a la luz de sus biografías (Batchelor, 2012: 181-182).

Aphra Behn fue una mujer poco convencional para su tiempo, que pudo vivir de forma independiente gracias a su trabajo como escritora. De manera que cuando se publicó su biografía, se trataba de justificar su conducta y de desacreditar habladurías y rumores, demostrando así cómo los relatos y obras dramáticas que escribió, en muchos casos de temas bastante escandalosos, se confundían con su vida privada, un hecho que se producía de forma prácticamente inmediata en el caso de las escritoras (Todd, 1989: 41), y que marcaría ostensiblemente toda su recepción posterior. Veremos esta particularidad mediante ciertos extractos de diversas biografías de la autora:

1- "Únicamente quiero salir en su defensa ante una injusta calumnia que recorre esta ciudad [...], no hubo ninguna relación entre el Príncipe [Oroonoko] y Astrea [Aphra Behn], [...] más que la generosa valoración de sus virtudes poco comunes" (Behn, 1735: $3-4)^{4}$.

2- "La conocí íntimamente y nunca vi nada impropio de la necesaria modestia de nuestro sexo, aunque sí era más alegre y libre de lo que la estupidez del escrupuloso permitiría" (Behn, 1735: 73).

3- "Se creía que su capacidad era superior a la de la mayoría de las de su sexo que se aventuraron a aparecer en público. Tenía dominio de la expresión y una fantasía desbordante. Escribía con facilidad, vivacidad y entusiasmo, especialmente sobre temas amorosos: podría considerársele la Safo inglesa" (Hays, 2013: 385).

4- "Si la señora Behn no hubiese estado tan impregnada por la disipación general y la endeble moralidad de su tiempo, su talento la habría situado mucho mejor en el escalafón de las escritoras" (Bethan, 1804: 111).

5- "Su padre [...] llevó consigo á Afara a Surinam, y allí inspiró la más viva pasión á un príncipe indígena llamado Oronoko, cuyas aventuras escribió después en un romance con aquel título" (Díez Canseco, 1844: I, 272-273).

6- "se la acusa de haber usado tanta licencia en sus escritos como en su conducta" (Díez Canseco, 1844: I, 273).

\footnotetext{
${ }^{4}$ Las traducciones de este y de los diversos textos que se incluyen a continuación de obras en inglés son mías.
} 
Por lo que se refiere al texto que se va a analizar, Oroonoko, incidiremos en contenidos relacionados con los diversos tipos de textos que influyeron en el nacimiento de la novela moderna, como cartas, textos periodísticos, de viajes, biográficos, o crónicas escandalosas, y que se aprecian en esta narración. Destacan especialmente todos aquellos recursos narrativos que aportan verosimilitud a lo que se cuenta, como en este caso la narración en primera persona por una participante y testigo de los hechos:

"No es mi intención, al contar la historia de este príncipe esclavo, entretener al lector con las aventuras de un héroe inventado cuya vida y andanzas pueden alterar la imaginación según el capricho del poeta ni, al contaros la verdad, intentar adornarla con ningún episodio sino con aquellos que en verdad le acontecieron. [...] Yo misma fui testigo de gran parte de lo que aquí se expone, y aquello que no pude presenciar lo escuché de boca del principal protagonista de la historia, el propio héroe, que nos contó todos los pormenores de su juventud" (Behn, 2000: 25).

En cuanto a los temas, estudiaremos con especial atención las cuestiones relacionadas con la esclavitud, destacando que se trata del primer texto de ficción narrativa inglesa en abordar la esclavitud de los africanos/as en las colonias americanas. Ya aparece claramente reflejado el triángulo comercial de esclavos/as de la época y su funcionamiento, con sus tres vértices en Europa, África y las colonias caribeñas. En estas zonas de contacto en las que personas procedentes de lugares separados por su geografía e historia entran en contacto se establecen relaciones que normalmente entrañan condiciones coercitivas, desigualdades extremas y conflictos insalvables (Pratt, 1992: 6). Oroonoko muestra esta colisión en numerosos pasajes, destacando la escena final en la que se narra la brutal muerte del protagonista a manos de los colonos blancos:

"Y entonces llegó el verdugo y primero le cortó los genitales y los arrojó al fuego. Luego le cortaron la nariz y las orejas con cuchillo herrumbroso y las quemaron. Él siguió fumando como si no pasara nada. Después le seccionaron un brazo, y aún así se mantuvo erecto y sosteniendo la pipa. Pero al cortarle el otro hundió la cabeza, dejando caer la pipa, y entregó su espíritu, sin quejido ni reproche” (Behn, 2000: 74).

Llegados a este punto y retomando nuevamente el enfoque didáctico presentado por Buccola (2003: 148), los y las estudiantes deberán ejercer un rol más activo y desarrollar su propio potencial investigador. Además, los documentos legales educativos indican que tras la lectura y comentario de ciertos fragmentos de los textos propuestos en gran grupo durante la clase, el alumnado deberá preparar su propia presentación oral o escrita. Por lo que se refiere a Aphra Behn y su relato Oroonoko, podrán elegir, por ejemplo, entre analizar un fragmento o un aspecto específico del texto, o indagar sobre alguna particularidad del estilo, la temática o la vida de la autora. Estas presentaciones servirán a su vez al profesorado como el principal 
recurso de evaluación de la propuesta; si bien, también se tendrá en cuenta el trabajo de los alumnos y alumnas en clase, especialmente la pertinencia y calidad de sus aportaciones durante las sesiones de comentarios en grupo.

\section{Charlotte Lennox}

Al igual que en el caso de la autora anterior, serán los alumnos y alumnas quienes descubran a esta escritora a través de sus pesquisas navegando en Internet y visitando páginas web, como las citadas más arriba. Aunque en este caso sea interesante para el alumnado, en el sentido de que así esta escritora les resultará más cercana, si la presentamos como la autora de una obra titulada The Female Quixote y que comenten lo que esto les sugiere, pues es evidente su relación con el Quijote de Cervantes, una obra central en la literatura española y que evidentemente conocen. En cualquier caso, al igual que con Behn, veremos qué aspectos de su vida se destacan y repiten en biografías de la época, lo que nos proporcionará más datos que agregar a los vistos anteriormente con Behn, respecto de la consideración de las escritoras de la época.

Charlotte Lennox fue también una mujer que se dedicó a la escritura por motivos económicos, aunque no cabe duda de su talento. Diversas circunstancias familiares, y especialmente su matrimonio, se mencionan como las causantes de su penuria económica, dado que tenía una familia a la que mantener y su marido estaba continuamente endeudado. Por ello, durante toda su carrera literaria, se centró en cultivar sus relaciones con eminentes miembros de los círculos literarios londinenses, como Samuel Johnson, Samuel Richardson y Henry Fielding, así como en la búsqueda de personas de la nobleza que pudieran ejercer de mecenas de su obra o de ella misma.

Como vemos, las mujeres no sólo debían desplegar todos sus talentos en la creación literaria, sino también para conseguir benefactores o benefactoras, que pudieran asistirles en la publicación de sus obras. Si en líneas generales esta era una ardua tarea, en el caso de las mujeres era aún más dificultosa, precisamente por su dependencia de los hombres. Pero como le ocurrió a Lennox, los esfuerzos no siempre daban los frutos esperados. Así, las biografías que se publicaron tras su muerte en la prensa y en colecciones biográficas hacen referencia a sus contactos y la protección y ayuda que le brindaron; sin embargo, a pesar de sus esfuerzos y su dilatada carrera, con numerosas publicaciones de diversa índole, no consiguió evitar morir en la pobreza:

1- "Esta señora, que fue muy distinguida en el mundo literario por su extraordinario mérito, tuvo el honor de ser la protegida del Dr. Johnson" (Schürer, 2008: 214).

2- "El mecenazgo que recibió de autores de reputación reconocida, junto con el entusiasmo de un público perspicaz, deberían haberle asegurado una situación económica desahogada; pero por diversas razones este no ha sido el caso. La última parte de su vida se 
vio ensombrecida por la enfermedad y la penuria, y su principal sustento provino de la Institución caritativa del Fondo Literario" (Schürer, 2008: 216).

3- "[...] habiendo quedado sin padres y sin fortuna, se vio obligada a buscar en el ejercicio de sus talentos los recursos que necesitaba para subsistir. [...] en los últimos años de su vida se vio expuesta á la miseria; pero los auxilios que la suministró la sociedad literaria la pusieron al abrigo de las necesidades extremas: [...] Richardson y Johnson apreciaban mucho los talentos de esta escritora” (Diez Canseco, 1844: II, 539-540).

Por lo que se refiere al texto seleccionado, The Female Quixote, uno de los aspectos que convendría destacar y que lo vincula directamente con la novela de Cervantes que Lennox toma como modelo, estaría relacionado con la lectura de cierto género de relatos, que en el texto cervantino son las novelas de caballerías, mientras que en el caso del relato de Lennox son los romances, en los que se idealizan las relacionas románticas de las protagonistas. No en vano la heroína del texto inglés, Arabela, es una joven cuyo principal pasatiempo consiste en leer este tipo de obras, que había heredado de su difunta madre y a las que fácilmente podía acceder en su biblioteca. De forma similar a lo ocurrido al hidalgo manchego, pronto se deja sentir la influencia de sus lecturas en el pensamiento y comportamiento de Arabela:

"Influidas por su modo de vida y los objetos que la rodeaban, las ideas de la joven pronto adquirieron un tinte romántico $\mathrm{y}$, convencida de que los romances contenían los retratos verídicos de la vida humana, encontró en ellos la fuente de todos sus pensamientos y esperanzas. En ellos aprendió a creer que el amor es el principio que gobierna el mundo, que cualquier otra pasión se subordinaba a él, y que es la causa de toda felicidad y miseria humana" (Lennox, 2004: 85-86).

El texto de Lennox instauró así en Inglaterra un Quijote femenino que perdurará a lo largo de la segunda mitad del siglo XVIII y de las primeras décadas del XIX. Una de las causas que se señalan para la presencia de estas novelas que utilizaron el modelo cervantino para destacar la perniciosa influencia que ciertas lecturas podían ejercer en las jóvenes lectoras, sería la preocupación existente ante el elevado número de lectoras debido al incremento en la tasa de alfabetización. Además, se recelaba de la gran facilidad con la que las jóvenes podían acceder a las novelas, principalmente a través de las bibliotecas de préstamo (Lasa Álvarez, 2007: 448). Sin embargo, al mismo tiempo que advertían sobre este peligro, The Female Quixote y otros textos similares describen unas protagonistas femeninas que, frente a la pasividad y a la reclusión al ámbito doméstico como ideales femeninos de la época, son capaces de acceder a una cierta movilidad y autonomía, actuando por sí mismas aunque sea a través de sus fantasías (Pawl, 2009: 166). Esto es posible por el comportamiento que muestran estas jóvenes, entre ellas nuestra protagonista Arabela, pues al igual que Don Quijote, sus lecturas les llevan a vivir en un mundo figurado, que Lennox objeta utilizando los mismos recursos de los romances que 
se están cuestionando, pero infundiéndoles un carácter paródico. Así, Arabela, de manera similar al viejo hidalgo creado por Cervantes, llevada por su obsesión ve como reales fantasías creadas por su imaginación, especialmente todas aquellas relacionadas con el amor. Resulta ilustrativo el episodio en el que Arabela cree que un joven jardinero que trabaja en su casa es en realidad el hijo de una familia noble que oculta su verdadero origen:

"Tras haber detectado tantas marcas de un nacimiento que no pudo ser humilde, le fue fácil pasar de la opinión de que era un caballero a la creencia de que algo más había en él, y cada vez que le veía ganaba solidez la sospecha, por lo que no tardó en convencerse rotundamente de que se trataba de una persona de rango, que, disfrazada de jardinero, se había colado al servicio de su padre, para así tener oportunidad de declararle su pasión, que debía desde luego ser grande, pues le había obligado a adoptar un aspecto indigno de su noble ascendencia" (Lennox, 2004: 101-102).

Esta y otras ocurrencias de la protagonista resultan, del mismo modo que en el Quijote, el desencadenante de numerosas escenas cómicas en las que Arabela interpreta la realidad según el modelo de los romances heroicos franceses.

Una vez examinados y comentados estos aspectos de la novela de Lennox en clase, como se propuso para el estudio de Aphra Behn y su texto Oroonoko, se pasará a una segunda fase en que será el alumnado quien tomará las riendas del estudio de esta autora y su obra, y abordarán un pequeño trabajo de investigación sobre alguna particularidad de la autora y su procedimiento creativo, o sobre algún tema o fragmento de The Female Quixote.

\section{Conclusiones}

Como ha ocurrido tradicionalmente en la historia literaria, en este trabajo se ha podido apreciar claramente que la mujer como escritora aparece esporádicamente y en muchos casos desconectada del resto de escritores varones en los libros de texto y manuales en general. Esta poca visibilidad se intenta solventar mediante apartados especiales dedicados a ellas o mediante la inclusión de imágenes y retratos de mujeres, al ser en muchos casos ellas la inspiración de los autores. Igualmente, estos temas escasamente presentes en el currículo suelen cobrar protagonismo puntualmente mediante dos procedimientos: "El día de...” y la asignaturización, y quedan así relegados del temario principal (Torres Santomé, 2010: 229-230). Por tanto, suele ser habitual que con motivo del Dia de la Mujer, por ejemplo, se realicen propuestas específicas dentro del ámbito literario en las que se estudian algunas voces femeninas destacadas, con el fin de contrarrestar ese silencio constatable, pero no dejan de ser acciones ocasionales, sin mayores consecuencias. 
Es por ello que en este trabajo se han ofrecido una serie de claves para la incorporación de las escritoras al currículo literario, y en concreto a la asignatura de Literatura Universal de Bachillerato. El profesorado tiene así la posibilidad de cuestionar los contenidos que una tradición sexista y patriarcal ha impuesto en los currículos, dando visibilidad necesaria a las escritoras y valorando en su justa medida sus aportaciones a la historia de la literatura. Pero no sólo se debe incluir sin más ciertas escritoras con sus respectivas obras entre los contenidos de la asignatura, sino que es también imprescindible una reflexión sobre los motivos por los que las mujeres se han dedicado en menor medida a la escritura, todos los impedimentos que han tenido que superar, y finalmente, cuando han llegado a publicar sus textos, analizar las razones por las que se las ha marginado y silenciado.

A través de esta propuesta quedan patentes las posibilidades que ofrece la didáctica de la literatura para una educación en valores, puesto que en el aula de Literatura Universal los y las estudiantes pueden conocer y valorar, no sólo la aportación de la mujer al ámbito literario, en particular al nacimiento de la novela moderna inglesa y europea y su desarrollo, sino también la difícil situación de las mujeres en una época histórica en la que únicamente podían vivir de forma digna si dependían de un hombre - primero, su padre y luego, su marido o hermanos. De lo contrario, tenían que sobrevivir mediante trabajos escasamente remunerados o poco respetables.

Aphra Behn lo intentó, trató de llevar una vida independiente y lo consiguió a través de la escritura y con cierto éxito. Sin embargo, la sociedad de su tiempo y la crítica en particular, no se lo pusieron fácil, como se ha podido observar más arriba. En cuanto a Charlotte Lennox, no cejó tampoco en su empeño por tratar de crearse una carrera literaria y porque sus trabajos fueran apreciados y valorados en su justa medida. Su situación personal difícil y su condición de mujer la llevaron a recurrir a las grandes personalidades literarias del momento y sin duda, sus creaciones llamaron su atención y consiguió su apoyo. Con todo, no consiguió escapar de la pobreza al final de sus días.

Además de para reflexionar sobre temas de género, esta propuesta resulta útil también para trabajar en el aula temas cruciales que han marcado la historia y la cultura contemporáneas, como son la colonización y la esclavitud. Mucho se ha hablado sobre la actitud de Behn hacia la esclavitud en Oroonoko, pues a pesar de las crudas escenas que en este texto se narran, no se aprecia una denuncia explícita de la escritora contra este denigrante comercio humano (Spencer, 2000: 232). Con todo, lo que no ofrece dudas es la repercusión posterior del texto y su utilización como emblema de la lucha abolicionista (Spencer, 2000: 265). Por otro lado, y con respecto a la novela de Lennox, nos puede permitir analizar y discutir temas de actualidad, pues la inquietud que se observaba en la segunda mitad del siglo XVIII por los efectos perniciosos de novelas y romances en las jóvenes lectoras, sería equiparable a la desconfianza que en la actualidad se observa ante las nuevos medios de comunicación e información y sus consumidores y consumidoras, especialmente en relación con ciertos programas de televisión o contenidos y páginas de Internet, y su posible influencia negativa en los y las jóvenes. 


\section{BIBLIOGRAFÍA}

- Abilleira Sanmartín, Xosé y Gestido de la Torre, Eloi (2009): Literatura Universal. Vigo: Xerais.

- Alonso Sánchez, María José (2002): "Las Académicas. Profesorado universitario y género". En: Revista de Educación, nº 328, pp. 465-475, [en línea] Disponible en: http://www.mecd.gob.es/dctm/revista-de-

educacion/articulosre228/re3282510861.pdf?documentId=0901e72b81259419 [20-11-2015].

- Arévalo Martín, Beatriz et al. (2015): Literatura Universal. Barcelona: Casals.

- Batchelor, Jennie (2012): "Jane Austen and Charlotte Smith: Biography, Autobiography and the Writing of Women's Literary History". En: Daniel Cook y Amy Culley (eds.): Women's Life Writing, 1700-1850. Gender, Genre and Authorship. Basingstoke: Palgrave, pp. 181-196.

- Behn, Aphra (1735): All the Histories and Novels Written by the Late Ingenious Mrs. Behn, Intire in Two Volumes. Vol. I. $8^{\mathrm{a}}$ ed. Londres: Charles Gildon.

. (2000): Oroonoko o el príncipe esclavo. La hermosa casquivana. Juan Jesús Zaro (trad.). Málaga: Servicio de Publicaciones de la Universidad de Málaga.

- Betham, Mary Matilda (1804): Biographical Dictionary of the Celebrated Women of Every Age and Country. Londres: B. Crosby \& Co.

- Blog "Eduideas" (2015): "La LOMCE y los currículos sobrecargados: filosofía y literatura”, [en línea] Disponible en: http://eduideas2.blogspot.com.es/2015/01/la-lomce-y-curriculossobrecargados.html [11-12-2015].

- Blog "Me sé cosicas" (2014): "La situación de la Literatura Universal en la LOMCE", [en línea] Disponible en: http://mesecosicas.blogspot.com.es/2014/06/la-situacion-de-la-literaturauniversal.html [09-09-2015].

- Buccola, Regina M. (2003): “These So-Called Early Modern Women Writers': Strategies for Integrating Women Writers into English Department Curriculum". En: Sixteenth Century Journal, vol. 34, n'.1, pp. 147-154.

- Coffey, Amanda y Delamont, Sara (2000): Feminism and the Classroom Teacher. Research, Praxis and Pedagogy. Londres y Nueva York: Routledge.

- D’haen, Theo; Domínguez, César y Thomsen, Mads Rosendahl (2013) (eds.): World Literature: A Reader. Londres y Nueva York: Routledge.

- De Riquer, Martín y Valverde, José María (2010): Historia de la literatura universal. 2 vols. Nueva ed. actualizada. Madrid: Gredos.

- Diard, Pascal y Bordons, Glòria (2005): "Descubrir un autor: un taller de lectura en torno a la obra del poeta palestino Mahmud Darwix”. En: Glòria Bordons y Anna Díaz-Plaja (coords.): Enseñar literatura en Secundaria. La formación de lectores críticos, motivados y cultos. Barcelona: Graó, pp. 69-80.

- Díez Canseco, Vicente (1844): Diccionario biográfico universal de mujeres célebres. 2 vols. Madrid: José Félix Palacios. 
- Espigado Tocino, Gloria (2004): "Historia y genealogía femenina a través de los libros de texto". En: Carmen Rodríguez Martínez (comp.): La ausencia de las mujeres en los contenidos escolares. Madrid: Miño y Dávila, pp. 113-144.

- Freixas, Laura (2005): "Mujeres y cultura: una breve arqueología de la misoginia reinante". En: Letras libres, $\mathrm{n}^{\mathrm{o}}$. 49, [en línea] Disponible en: http://www.letraslibres.com/revista/convivio/mujeres-y-cultura-una-breve-arqueologia-de-lamisoginia-reinante [26-01-2016].

. (2009): La novela femenil y sus lectrices. La desvalorización de las mujeres y lo femenino en la crítica literaria actual. Córdoba: Servicio de Publicaciones de la Universidad de Córdoba.

. (2013): “Qué fue de las escritoras”. En: El País, 6 de julio, [en línea] Disponible en: http://elpais.com/elpais/2013/06/25/opinion/1372182616_612684.html [03-08-2013].

- Fuentes Moreno, Jazmina (2013): "Educación literaria y democracia: El taller educativo con perspectiva de género en la ESO". En: Revista de Didácticas Específicas, nº. 8, pp. 81-98, [en línea] Disponible en: http://digitooluam.greendata.es//exlibris/dtl/d3_1/apache_media/L2V4bGlicmlzL2R0bC9kM18xL2FwYWNo ZV9tZWRpYS82MzU5Nw==.pdf [11-02-2014].

- Guillén, Claudio (2013): “Weltliteratur (1991)”. En: Theo D’haen, César Domínguez y Mads Rosendahl Thomsen (eds.): World Literature: A Reader. Londres y Nueva York: Routledge, pp. 142-149.

- Guillory, John (1993): Cultural Capital. The Problem of Literary Canon Formation. Chicago y Londres: The University of Chicago Press.

- Gutiérrez Ordóñez, Salvador; Hernández García, Jesús y Serrano Serrano, Joaquín (2015): Literatura Universal. Madrid: Anaya.

- Heredero de Pedro, Carmen (2013) (dir.): Otras miradas. Aportaciones de las mujeres a la lengua y literatura castellanas. Madrid: Federación de Enseñanza de CCOO, [en línea] Disponible

en: http://www.fe.ccoo.es/comunes/recursos/25/pub90783_Otras_miradas._Aportaciones_de_las_m ujeres_a_la_lengua_y_literatura_castellanas.pdf [16-01-2016].

- Hernández Martín, Azucena; García-Valcárce Muñoz-Repiso, Ana y Sánchez Gómez, María Cruz (2004): "El profesorado universitario desde una perspectiva de género". En: Revista de Educación, vol. 28, $\mathrm{n}^{\mathrm{o}}$. 2, pp. 105-143, [en línea] Disponible en: http://www.redalyc.org/pdf/440/44028207.pdf [20-11-2015].

- Instituto de la Mujer (2000): La transmisión de los modelos femenino y masculino en los libros de la enseñanza obligatoria. Madrid: Instituto de la Mujer.

- Hays, Mary (2013): Female Biography; or, Memoirs of Illustrious and Celebrated Women, of All Ages and Countries. Alphabetically Arranged. Vol. I. Gina Luria Walker (ed.). Londres: Pickering \& Chatto.

- Lasa Alvarez, Begoña (2007): "El personaje de Don Quijote como referente en las novelistas en lengua inglesa de finales del siglo XVIII y principios del XIX”. En: José Manuel Barrio Marco y María José Crespo Allué (eds.): La huella de Cervantes y del Quijote en la cultura anglosajona. Valladolid: Universidad de Valladolid, Centro Buendía, pp. 447-455. 
. (2010): "Reviewing Women in the Long Eighteenth Century: A Question of Inequality". En: Ana Antón-Pacheco et al. (eds.): Differences, (In)Equality and Justice. Estudios de Mujeres. Vol. VII. Madrid: Editorial Fundamentos, pp. 191-199.

- Lennox, Charlotte (2004): La mujer Quijote. Cristina Garrigós (ed.). Madrid: Cátedra.

- Ley Orgánica 8/2013, de 9 de diciembre, para la Mejora de la Calidad Educativa (BOE nº. 295, 10 de diciembre de 2013), [en línea] Disponible en: https://www.boe.es/boe/dias/2013/12/10/pdfs/BOE-A-2013-12886.pdf [22-01-2016].

- Llovet, Jordi (2012) (ed.): Lecciones de literatura universal. 4ª ed. Madrid: Cátedra.

- López Navajas, Ana (2014): “Análisis de la ausencia de las mujeres en los manuales de la ESO: una genealogía de conocimiento ocultada". En: Revista de Educación, no . 363, [en línea] Disponible en: http://www.revistaeducacion.mec.es/doi/363_188.pdf [02-09-2015].

- Pawl, Amy J. (2009): "Feminine Transformations of the Quixote in Eighteenth-Century England: Lennox's Female Quixote and Her Sisters". En: J.A.G. Ardila (ed.): The Cervantean Heritage. Reception and Influence of Cervantes in Britain. Londres: Legenda, pp. 166-175.

- Pizer, John (2006): The Idea of World Literature. History and Pedagogical Practice. Baton Rouge: Louisiana State University Press.

- Posteguillo, Santiago (2012): La noche en que Frankenstein leyó el Quijote. La vida secreta de los libros. Barcelona: Planeta.

- Pratt, Mary Louise (1992): Imperial Eyes. Travel Writing and Transculturation. Londres y Nueva York: Routledge.

- Real Decreto 1105/2014, de 26 de diciembre, por el que se establece el currículo básico de la Educación Secundaria Obligatoria y del Bachillerato (BOE ${ }^{\circ}$. 3, 3 de enero de 2015), [en línea] Disponible en: http://www.boe.es/boe/dias/2015/01/03/pdfs/BOE-A-2015-37.pdf [15-092015].

- Reyzábal, Ma Victoria (2012): Canon literario y diferencia de género en la educación. Madrid: La Muralla.

- Rivero Santamaría, Diana (2014): "División sexual del periodismo. Ellas a las aulas y ellos a las redacciones: Estudio del caso vasco". En: Cuestiones de género: de la igualdad y de la diferencia, $\mathrm{n}^{\circ} . \quad 9, \quad \mathrm{pp}$. 259-285, [en línea] Disponible en: http://revpubli.unileon.es/ojs/index.php/cuestionesdegenero/article/view/989/1029 [13-122015].

- Rodríguez Martínez, Carmen (2006): “Introducción. El currículo, el género y la igualdad”. En: Carmen Rodríguez Martínez (comp.): Género y currículo. Aportaciones del género al estudio y práctica del currículo. Madrid: Akal, pp. 9-16.

- Schürer, Norbert (2008) (ed.): Sophia, de Charlotte Lennox. Peterborough, Ontario: Broadview Press.

- Servén Díez, Carmen (2008): “Canon literario, educación y escritura femenina”. En: Ocnos. Revista de estudios sobre lectura, $\mathrm{n}^{\mathrm{o}}$. 4, pp. 7-20, [en línea] Disponible en: http://www.revista.uclm.es/index.php/ocnos/article/view/195/175 [15-01-2014].

- Skinner, John (2001): An Introduction to Eighteenth-century Fiction. Raising the Novel. Basingstoke: Palgrave. 
- Soldevila, Llorenç (2006): "Enseñar Historia de la Literatura en el segundo ciclo de la ESO”. En: Glòria Bordons y Anna Díaz-Plaja (coords.): Enseñar literatura en Secundaria. La formación de lectores críticos, motivados y cultos. Barcelona: Graó, pp. 19-31.

- Spencer, Jane (1986): The Rise of the Woman Novelist. From Aphra Behn to Jane Austen. Oxford y Nueva York: Basil Blackwell. . (2000): Aphra Behn's Afterlife. Oxford: Oxford University Press.

- Spender, Dale (1986): Mothers of the Novel. 100 Good Women Writers before Jane Austen . Londres: Pandora.

- Todd, Janet (1989): The Sign of Angellica. Women, Writing and Fiction, 1660-1800. Londres: Virago.

- Torres Santomé, Jurjo (2003): El curriculum oculto. $7^{\mathrm{a}}$ ed. Madrid: Morata. Morata. . (2010): La justicia curricular. El caballo de Troya de la cultura escolar. Madrid:

- Warner, William B. (2005): "Novels on the Market". En: John Richetti (ed.): The Cambridge History of English Literature, 1660-1780. Cambridge: Cambridge University Press, pp. 87-105.

- Weiner, Gaby (1999): Los feminismos en la educación. Morón, Sevilla: Publicaciones M.C.E.P.

- Woolf, Virginia (2008): Una habitación propia. Barcelona: Seix Barral, [en línea] Disponible en: http://biblio3.url.edu.gt/Libros/wilde/habitacion.pdf [17-01-2014]. 